\title{
Photochemical Fragmentation of Irgacure PAG 103
}

\author{
M. John Plater, *ํㅏㅇ William T. A. Harrison, ${ }^{\circledR}$ and Andrea Raab \\ Department of Chemistry, University of Aberdeen, Meston Walk, Aberdeen, Scotland AB24 3UE, U.K.
}

\section{Supporting Information}

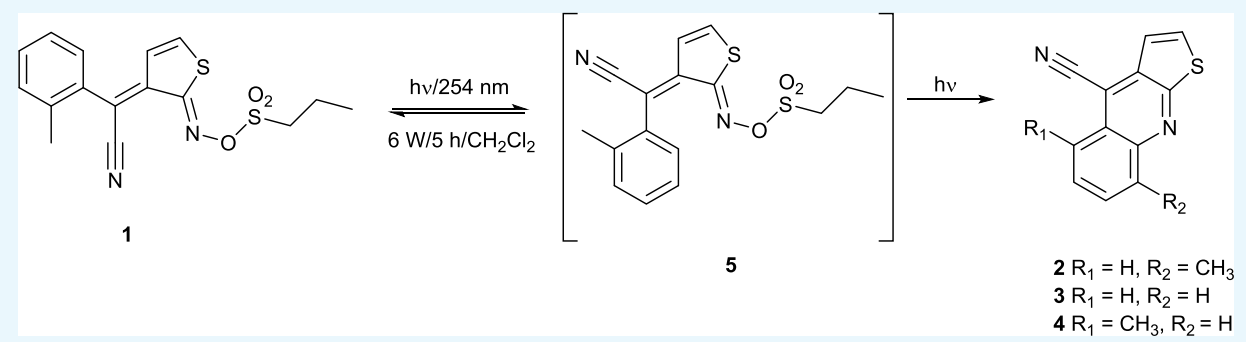

ABSTRACT: Photoisomerization of Irgacure PAG 103 followed by photocyclization and fragmentation leads to three tricyclic thieno[2,3-b] quinoline-4-carbonitrile heterocyclic compounds. The release of acid which can catalyze polymer resist modifications is indicated by the low $\mathrm{pH}$ of an aqueous extract. These reactions are discussed in view of possible mechanisms and how these might influence future design strategies.

\section{INTRODUCTION}

The concept of chemical amplification in thin polymer film resists was proposed by Ito, Willson, and Fréchet in 1982., Chemical amplification allows a single photochemical reaction to induce a cascade of transformations in a resist film which modify its properties during a postexposure bake. ${ }^{3-5}$ Photoacid generators (PAGs), which release catalytic quantities of acid upon irradiation through a mask, have become a new family of modern polymer resist. Various PAGs have been synthesized for use in chemical amplification resists. ${ }^{6,7}$ They can be divided into two main types, ionic and nonionic. Ionic or onium salt acid generators such as triarylsulfonium and diaryliodonium salts were originally developed by Crivello for curing epoxy resins. $^{8-15}$ Upon irradiation, they liberate strong acids with good quantum yields. Nonionic PAGs include oxime sulfonates, ${ }^{16-19}$ oxime esters, ${ }^{20}$ and $\mathrm{N}$-sulfonyloxyimides. ${ }^{21}$ The choice of PAG for an application depends upon many factors such as the wavelength of radiation, ${ }^{22-27}$ quantum efficiency of acid generation, solubility in the casting solvent, ${ }^{28}$ thermal and hydrolytic stability, toxicity, strength of the liberated acid, ${ }^{3-5}$ line width, ${ }^{29}$ acid diffusion, ${ }^{30}$ and environmental considerations. ${ }^{31,32}$ Although the mechanism of the photochemical decomposition of Crivello salts has been studied, ${ }^{3-5}$ less is known about how nonionic PAGs release acid. In this paper, a commercial UV light PAG called Irgacure PAG $103^{33-37}$ is examined and key photochemical decomposition products are characterized.

\section{RESULTS AND DISCUSSION}

A batch of compound 1, known as Irgacure PAG 103, was generously supplied to us for study from a UK division of BASF in Cheadle. This compound, which is soluble in organic solvents, can be used in polymer resists to produce a positive image and for the curing of resins. It has been the subject of numerous patents. ${ }^{33-37}$ However, to date, we have found no published synthesis or data for this compound and only one study of its degradation by photochemical irradiation to give two products. $^{38}$ The two products were characterized by advanced NMR, and it was not concluded that this PAG 1 released acid upon irradiation. Here, we report an additional degradation product, and a mechanism is proposed to explain how these may form. Two of the degradation products and the stereochemistry of the starting material, were verified by X-ray single crystal structure determinations. This information is relevant because it helps to understand how acid is released from it and what structural features are important for this particularly because the design of photoacid releasing compounds ${ }^{39-41}$ remains a topical subject both academically and commercially. ${ }^{3-5}$ Compound $\mathbf{1}$ was irradiated with a low power $6 \mathrm{~W}$ UV lamp at $254 \mathrm{~nm}$ in an immersion well. This setup is user friendly and is suitable for undergraduates; it is air cooled by a fume hood fan and it avoids a powerful $400 \mathrm{~W}$ medium pressure mercury lamp inside an immersion well containing a large volume of flammable solvent. The solution was not deoxygenated because some PAGs operate in thin films in air. The products $\mathbf{2 - 4}$ were purified by chromatography on silica gel (Figure 1).

Figure 2 shows the molecular structure of the starting material $\mathbf{1}$ and the molecular structures of two products $\mathbf{2}$ and 4. Figure 2 Top shows the starting material $\mathbf{1}$. Analysis by thinlayer chromatography showed that the two products were successfully separated by chromatography. The front less polar spot was fully characterized spectroscopically, and the structure was confirmed as compound $\mathbf{2}$ by an X-ray single crystal

Received: August 30, 2019

Accepted: October 31, 2019

Published: November 12, 2019 

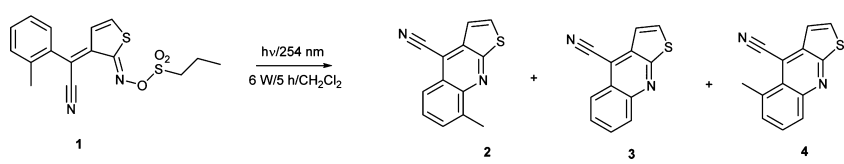

Figure 1. Photochemical decomposition of Irgacure PAG 1031. Yields: $\mathbf{2}(25 \%) ; 3+4(60 \%)$. Compound 1 was irradiated with a $6 \mathrm{~W}$ $254 \mathrm{~nm}$ UV lamp in an immersion well.
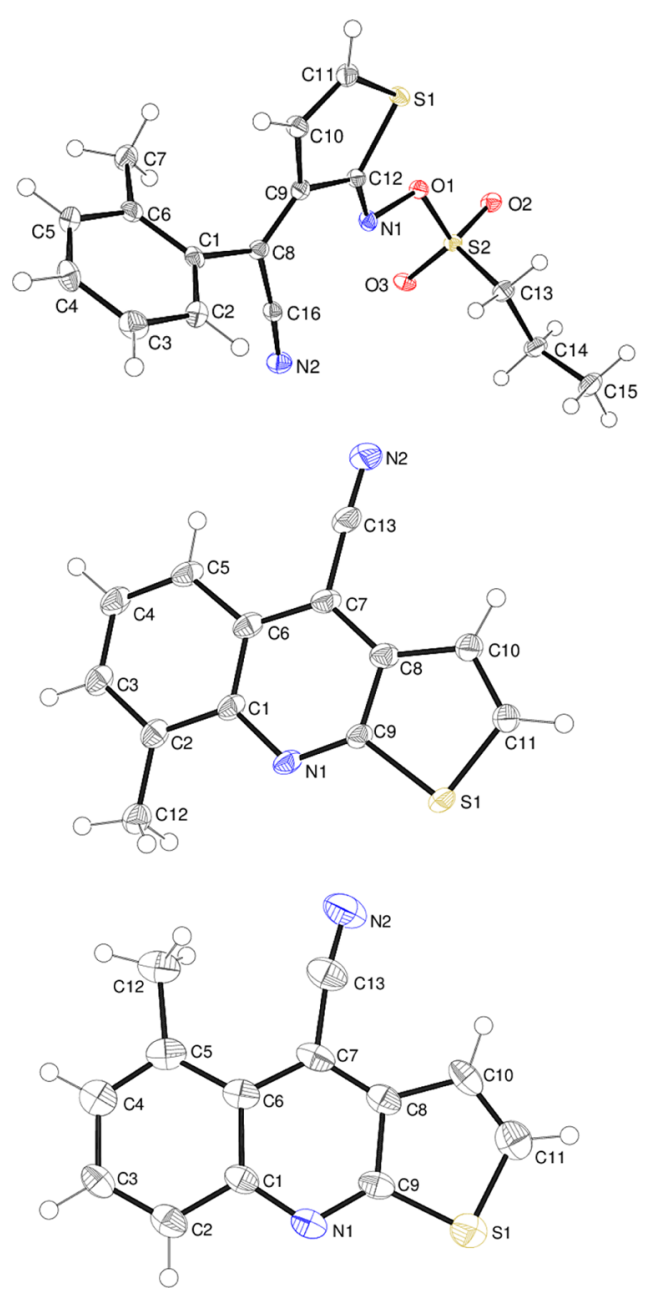

Figure 2. Top: molecular structure of Irgacure PAG 103 (molecule C1) 1; middle: photochemical decomposition product 2 ; and bottom: photochemical decomposition product 4 . Figures show 50\% displacement ellipsoids in each case.

structure determination (Figure 2 middle). This corroborates the literature result. However, the more polar spot was an inseparable mixture of compounds 3 and $\mathbf{4}$ which were separated and analyzed by liquid chromatography-mass spectrometry (LC-MS) (Figure S1 and Table S1) and characterized spectroscopically as an approximately equal mixture of two compounds (Supporting Information). Compound 3 had the expected molecular mass of 211; it lacked a methyl group and only one methyl group was present in the proton and carbon NMR spectra which belonged to compound 4. Selective crystallization gave crystals which solved for one of the components, compound 4 (Figure 2 bottom). The absence of compound 3 in the previous study is unknown.

Figure 3 shows a mechanism for the formation of products 2 and 3. The starting material must first undergo a UV light catalyzed $Z / E$ isomerization to a less favorable isomer $\mathbf{5}$. Presumably structure $\mathbf{1}$ is the preferred thermodynamic isomer because the nitrile aligns with the oxime nitrogen atom rather than the more bulky aryl ring and the thioenol ether is trans to the nitrile. Light-catalyzed cis-trans isomerizations of stilbenes are well documented in the literature. ${ }^{42,43}$ Intermediate 5 could undergo a $6 \pi$ electrocyclisation, as shown, which involves the oxime sulfonate forming a ring at the ipso site carrying the methyl group. Intermediate 6 could fragment to a resonancestabilized carbocation 7 , assisted by the electron rich thiophene ring, followed by a migration of the methyl group to intermediate 9 and finally loss of the proton forming product $\mathbf{2}$ and propylsulfonic acid 8. Product $\mathbf{2}$ has a migrated methyl group which allows the system to aromatize. Migration of the methyl group is more suited to a rearranging carbocation because carbocations are prone to rearrange and require the ring to form first before fragmentation of the $\mathrm{N}-\mathrm{O}$ bond. Hence, the rearranged product is an indication of the mechanistic pathway. If intermediate 7 or 9 is demethylated by either the solvent, water, or the counterion $\mathbf{8}$, then, product 3 is formed. Product 3 might also form via homolytic fragmentation of the $\mathrm{N}-\mathrm{O}$ bond of compound 5 (not shown), followed by ipso cyclization of an aminyl radical and elimination of a methyl group free radical but this mechanism would not give product 2 . Products 2 and 3 can arise from the same reaction pathway. Aqueous extracts of the dichloromethane (DCM) solution were shown to be of low $\mathrm{pH}$ with universal indicator paper proving that acid is liberated in these reactions but it would be for forming product $\mathbf{2}$ and not necessarily for forming product 3 .

Figure 4 shows a mechanism for the formation of product 4 . Intermediate 5 could undergo a $6 \pi$ electrocyclization to give intermediate $\mathbf{1 0}$ which can give product $\mathbf{4}$ by a facile elimination of propylsulfonic acid 8. Hence, this pathway retains the aryl methyl group and is efficient in producing acid 8.

Both the mechanistic pathways in Figures 3 and 4 require the release of propylsulfonic acid. A crude reaction mixture was assayed by proton $\mathrm{NMR}$ in $\mathrm{CDCl}_{3}$ and $\mathrm{CD}_{3} \mathrm{OD}$ which showed the presence of propylsulfonic acid (Figures S16 and S17).

Crystal Structures. The asymmetric unit of 1 consists of three molecules, A, B, and C. They differ in the dihedral angles between the benzene and thiophene rings [69.53 (15), 55.64 (16), and $72.7(2)^{\circ}$ for $\mathrm{A}, \mathrm{B}$, and $\mathrm{C}$, respectively] and the conformation of the $\mathrm{O}-\mathrm{S}-\mathrm{C}-\mathrm{C}$ fragment of the propyl chain, which is anti in $\mathrm{A}$ [torsion angle $\left.=175.8(3)^{\circ}\right]$ and gauche in $\mathrm{B}$ and $C\left[-58.2(3)\right.$ and $-57.1(3)^{\circ}$, respectively]. Compound 2 crystallizes with one almost planar molecule in the asymmetric unit (rms deviation for the atoms in the fused rings $=0.009 \AA$ ), whereas the asymmetric unit of 4 consists of two molecules (Figures S2-S4).

\section{CONCLUSIONS}

Mechanisms are proposed for the photochemical fragmentation of the commercial photoacid generator Irgacure PAG 103 1. These are thought to be the first reactions of this type in organic systems. The pathways involve an unusual type of $6 \pi$ photocyclization reaction which involves cyclization of an oxime sulfonate followed by an elimination of propylsulfonic acid 8 which may catalyze polymer resist modification. The rearrangement product $\mathbf{2}$ suggests a carbocation pathway is involved; hence, the photocyclisation occurs first before fragmentation of the oxime $\mathrm{N}-\mathrm{O}$ bond which would involve 


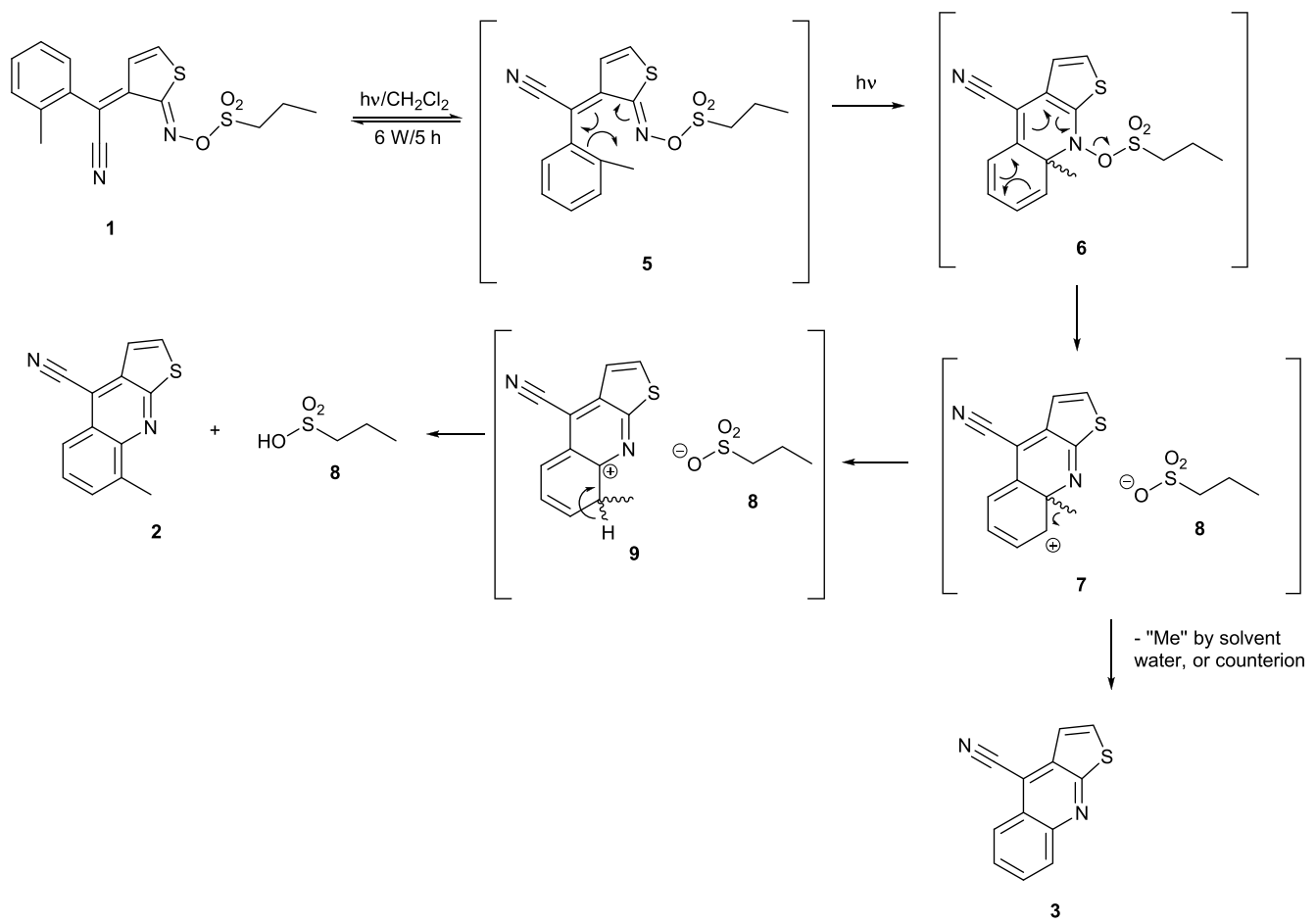

Figure 3. Mechanism proposed for the formation of products 2 and 3. Intermediates 5-9 have not been isolated.

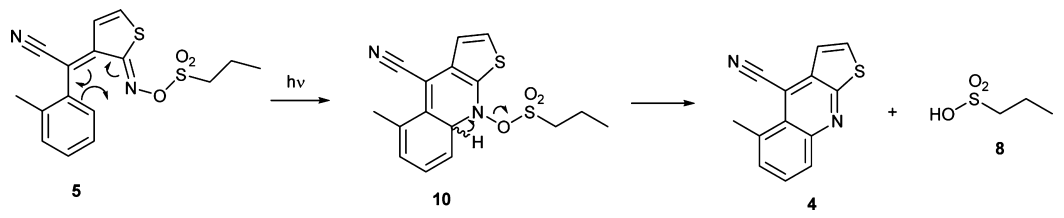

Figure 4. Proposed mechanism for the formation of product 4 .

free radicals rather than a carbocation. This mechanistic understanding may help in the future design of more efficient and sensitive PAGs for photocuring applications in polymer resists.

\section{EXPERIMENTAL SECTION}

General. IR spectra were recorded on an ATI Mattson FTIR spectrometer using $\mathrm{KBr}$ discs. UV spectra were recorded using a PerkinElmer Lambda $25 \mathrm{UV}$-vis spectrometer with $\mathrm{CH}_{2} \mathrm{Cl}_{2}$ as the solvent. ${ }^{1} \mathrm{H}$ and ${ }^{13} \mathrm{C}$ NMR spectra were recorded at 400 and $100.5 \mathrm{MHz}$, respectively, using a Varian 400 spectrometer. Chemical shifts, $\delta$, are given in ppm and measured by comparison with the residual solvent. Coupling constants, $J$, are given in $\mathrm{Hz}$. Low resolution and high resolution mass spectra were obtained at the University of Wales, Swansea, using electron impact ionization and chemical ionization. Melting points were determined on a Kofler hotstage microscope. Irgacure PAG 103 was donated from an agent of BTC. ${ }^{44}$

Liquid Chromatography-Mass Spectrometry. For analytical separation, an Agilent 1290 Infinity high-performance liquid chromatography (HPLC) system consisting of a quaternary HPLC pump, cooled autosampler compartment, column compartment, and diode-array UV-vis detector was used. A Kintex F5 column $(2.1 \times 150 \mathrm{~mm}$, Phenomenex, UK) was used for separation with a water/acetonitrile gradient (both $0.1 \% \mathrm{v} / \mathrm{v}$ formic acid) from $5 \%$ acetonitrile to $100 \%$ in

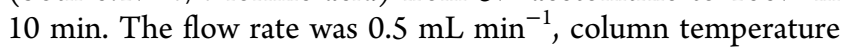

$40{ }^{\circ} \mathrm{C}$, and sample volume $5 \mu \mathrm{L}$. The mass spectrometer [electrospray MS (ES-MS)] used was a MAXIS II UHR-TOF LC-MS system (Bruker UK Ltd) with an ESI source connected to the UV-vis detector by a short length of Peektubing. The ES-MS was operated in a positive ion mode with a capillary voltage of $4.5 \mathrm{kV}$ using sodium formate clusters for calibration and methyl stearate as lock mass. Mass spectra were recorded automatically.

Data for Compound 1. (Z)-2-((Z)-2-(((Propylsulfonyl)oxy)imino)thiophen-3(2H)-ylidene)-2-(o-tolyl)acetonitrile 1 (Irgacure PAG 103). ${ }^{16} \mathrm{mp} 102-103{ }^{\circ} \mathrm{C} \lambda_{\max }(\mathrm{EtOH}) / \mathrm{nm}$ 405 ( $\log \varepsilon$ 3.9), 262 (3.93) and 226 (4.3); $\nu_{\max }(\mathrm{KBr}) / \mathrm{cm}^{-1}$ 3091w, 2964w, 2205w, 1524w, 1373s, 1320s, 1262s, 1167s, 853s, 807s, 769s, 730s, 710s, 684s, 674s, 615s, 600s, 560s, $521 \mathrm{~s}, 487 \mathrm{~s}$ and $460 \mathrm{~s} ; \delta_{\mathrm{H}}\left(400 \mathrm{MHz} ; \mathrm{CDCl}_{3}\right): 0.9(3 \mathrm{H}, \mathrm{t}, J=$ $8.0), 1.73-1.79(2 \mathrm{H}, \mathrm{m}), 2.16(3 \mathrm{H}, \mathrm{s}), 3.39(2 \mathrm{H}, \mathrm{t}, J=8.0)$, $5.96(1 \mathrm{H}, \mathrm{d}, J=8.5), 6.65(1 \mathrm{H}, \mathrm{d}, J=8.5), 6.99(1 \mathrm{H}, \mathrm{d}, J=$ $8.0)$; $7.05(1 \mathrm{H}, \mathrm{t}, J=8.0), 7.08(1 \mathrm{H}, \mathrm{d}, J=8.0)$ and $7.14(1 \mathrm{H}$, $\mathrm{t}, J=8.0) ; \delta_{\mathrm{C}}\left(100.1 \mathrm{MHz} ; \mathrm{CDCl}_{3}\right): 12.7,17.2,19.8,51.6$, $111.7,116.9$, 123.0, 126.5, 129.8, 130.4, 131.2, 132.6, 133.0, 136.8, 146.0 and 161.0; HRMS (orbitrap ASAP) $m / z:\left(\mathrm{M}^{+}+\right.$ $\mathrm{H}, 100 \%$ ) calcd for $\mathrm{C}_{16} \mathrm{H}_{16} \mathrm{~N}_{2} \mathrm{O}_{3} \mathrm{~S}_{2} \mathrm{H}, 349.0681$; found, 349.0682; $m / z:\left(\mathrm{M}^{+}+\mathrm{H}-\mathrm{CH}_{3} \mathrm{CH}_{2} \mathrm{CH}_{2} \mathrm{SO}_{3}, 40 \%\right)$ calcd for $\mathrm{C}_{13} \mathrm{H}_{8} \mathrm{~N}_{2} \mathrm{SH}, 225.0486$; found, 225.0486 .

Photochemical Irradiation of Irgacure PAG $103 .^{16} 8$ Methylthieno[2,3-b] quinoline-4-carbonitrile 2, a mixture of Thieno[2,3-b] quinoline-4-carbonitrile 3, and 5-Methylthieno[2,3-b] quinoline-4-carbonitrile 4 
Irgacure PAG $103^{17} 1(100 \mathrm{mg}, 0.29 \mathrm{mmol})$ in DCM (100 $\mathrm{mL}$ ) was irradiated for $5 \mathrm{~h}$ with a $6 \mathrm{~W} 254 \mathrm{~nm}$ lamp in a quartz immersion well without deoxygenation. Cooling was provided by a fume hood fan. The solution was extracted with $50 \mathrm{~mL}$ of dilute $\mathrm{KOH}(0.1 \mathrm{M})$, dried over $\mathrm{MgSO}_{4}$, and concentrated to $20 \mathrm{~mL}$. This clean reaction was purified by chromatography on silica gel. Light petrol: DCM (50:50; $150 \mathrm{~mL}: 150 \mathrm{~mL})$ eluted the first title compound $2(16 \mathrm{mg}, 25 \%)$ as a colorless solid, $\mathrm{mp} 206-207{ }^{\circ} \mathrm{C}$ (from DCM/light petroleum ether 40-60). $\lambda_{\max }(\mathrm{EtOH}) / \mathrm{nm} 357(\log \varepsilon 3.8)$ and $264(4.6) ; \nu_{\max }(\mathrm{KBr}) /$ $\mathrm{cm}^{-1} 3080 \mathrm{w}, 2221 \mathrm{w}, 1556 \mathrm{w}, 1475 \mathrm{w}, 1391 \mathrm{w}, 1370 \mathrm{w}, 1318 \mathrm{w}$, $1277 \mathrm{w}, 1256 \mathrm{w}, 1216 \mathrm{w}, 1160 \mathrm{w}, 1093 \mathrm{w}, 1032 \mathrm{w}, 901 \mathrm{w}, 820 \mathrm{w}$, $806 \mathrm{w}, 745 \mathrm{~s}, 734 \mathrm{~s}, 687 \mathrm{~s}, 623 \mathrm{w}, 610 \mathrm{w}$ and $518 \mathrm{w} ; \delta_{\mathrm{H}}(400 \mathrm{MHz}$; $\left.\mathrm{CDCl}_{3}\right) 2.83(3 \mathrm{H}, \mathrm{s}), 7.54(1 \mathrm{H}, \mathrm{d}, J=4.0), 7.57(1 \mathrm{H}, \mathrm{t}, J=4.0$ and 4.0$), 7.63(1 \mathrm{H}, \mathrm{d}, J=4.0), 7.83(1 \mathrm{H}, \mathrm{d}, J=4.0)$ and 8.10 $(1 \mathrm{H}, \mathrm{d}, J=4.0) ; \delta_{\mathrm{C}}\left(100.1 \mathrm{MHz} ; \mathrm{CDCl}_{3}\right): 18.4,111.1,115.4$, $119.8,123.0,124.1,128.2,130.4,132.7,133.7,137.6,145.3$ and 161.2; HRMS (orbitrap ASAP) $m / z:\left(\mathrm{M}^{+}+\mathrm{H}, 100 \%\right.$ ) calcd for $\mathrm{C}_{13} \mathrm{H}_{8} \mathrm{~N}_{2} \mathrm{SH}, 225.0486$; found, 225.0489. Then, DCM $(200 \mathrm{~mL})$ eluted the second title compound mixture $3+$ $4(37 \mathrm{mg}, 60 \%)$ as a colorless solid, broad $\mathrm{mp} 130-140{ }^{\circ} \mathrm{C}$ (from DCM/light petroleum ether 40-60). $\lambda_{\max }(\mathrm{EtOH}) / \mathrm{nm}$ $357\left(\log \varepsilon\right.$ 3.9) and $264(4.7) ; \nu_{\max }(\mathrm{KBr}) / \mathrm{cm}^{-1} 3099 \mathrm{w}$, $2218 \mathrm{w}, 1634 \mathrm{w}, 1548 \mathrm{w}, 1504 \mathrm{w}, 1474 \mathrm{w}, 1386 \mathrm{w}, 1319 \mathrm{w}, 1275 \mathrm{w}$, $1258 \mathrm{w}, 1223 \mathrm{w}, 1156 \mathrm{w}, 1088 \mathrm{w}, 1033 \mathrm{w}, 967 \mathrm{w}, 878 \mathrm{w}, 863 \mathrm{w}$, $810 \mathrm{w}, 762 \mathrm{~s}, 747 \mathrm{~s}, 681 \mathrm{~s}, 645 \mathrm{w}, 588 \mathrm{w}$ and $478 \mathrm{w} ; \delta_{\mathrm{H}}(400 \mathrm{MHz}$; $\left.\mathrm{CDCl}_{3}\right): 3.07(3 \mathrm{H}, \mathrm{s}), 7.41(1 \mathrm{H}, \mathrm{d}, J=8.0), 7.54(1 \mathrm{H}, \mathrm{d}, J=$ 8.0), $7.57(1 \mathrm{H}, \mathrm{d}, J=8.0), 7.62(1 \mathrm{H}, \mathrm{t}, J=8.0), 7.69(1 \mathrm{H}, \mathrm{t}, J=$ 8.0), 7.77-7.83 (2H, m), $7.84(1 \mathrm{H}, \mathrm{d}, J=8.0), 8.02(1 \mathrm{H}, \mathrm{d}, J=$ $8.0), 8.17(1 \mathrm{H}, \mathrm{d}, J=8.0)$ and $8.24(1 \mathrm{H}, \mathrm{d}, J=8.0) ; \delta_{\mathrm{C}}(100.1$ $\left.\mathrm{MHz} ; \mathrm{CDCl}_{3}\right): 22.3,109.6,111.0,115.0,117.8,119.8,120.7$, $122.8,124.0,125.1,128.1,128.4,129.3,130.0,130.3,130.5$, $133.2,133.5,133.9,134.5,135.3,145.8,147.0,161.0$ and 162.2; HRMS (orbitrap ASAP) $m / z:\left(\mathrm{M}^{+}+\mathrm{H}-\mathrm{CH}_{2}, 20 \%\right)$ calcd for $\mathrm{C}_{12} \mathrm{H}_{6} \mathrm{~N}_{2} \mathrm{SH}, 211.0330$; found, $211.0327 ; \mathrm{m} / z:\left(\mathrm{M}^{+}+\right.$ $\mathrm{H}, 100 \%$ ) calcd for $\mathrm{C}_{13} \mathrm{H}_{8} \mathrm{~N}_{2} \mathrm{SH}, 225.0486$; found, 225.0485 .

Crystallization Experiments. Compounds 1, 2, and 4 were crystallized by the same method. The compound $(75 \mathrm{mg})$ was dissolved in a small quantity of DCM (about $25 \mathrm{~mL}$ ) in a $50 \mathrm{~mL}$ beaker. This was then carefully diluted with light petroleum ether (40-60) until the solution turned hazy. A small amount of DCM was then added to turn the solution clear. This is then a good solvent composition to begin crystallization. The beaker was covered in aluminum foil that had some small holes in it, and the solution was left for a few days to evaporate the solvent. A sample of partially crystalline material, a mixture of compounds 3 and $\mathbf{4}$, was sent away for a data set, and this was successful. However, a partial, physical separation of material to give either pure 3 or $\mathbf{4}$ by NMR was not successful.

Intensity data for 1,2 , and 4 were collected at $T=100 \mathrm{~K}$ on a Rigaku AFC11 CCD diffractometer with $\mathrm{Cu} \mathrm{K} \alpha$ radiation $(\lambda$ $=1.54184 \AA$ ). The structures were solved by direct methods and optimized by refinement against $|F|^{2}$; the $\mathrm{H}$ atoms were geometrically placed and refined as riding atoms.

Crystal data for $1 \mathrm{C}_{16} \mathrm{H}_{16} \mathrm{~N}_{2} \mathrm{O}_{3} \mathrm{~S}_{2}, M_{\mathrm{r}}=348.43$, monoclinic, $C c$ (no. 9), $a=7.98090$ (10) $\AA, b=24.9093$ (4) $\AA, c=24.7994$ (3) $\AA, \beta=90.3360(10)^{\circ}, V=4930.00$ (12) $\AA^{3}, Z=12, R(F)=$ $0.047, w R\left(F^{2}\right)=0.105$, CCDC deposition number $=1915103$.

Crystal data for $2 \mathrm{C}_{13} \mathrm{H}_{8} \mathrm{~N}_{2} \mathrm{~S}, M_{\mathrm{r}}=224.27$, monoclinic, $P 2_{1} /$ $n$ (no. 14), $a=3.82113$ (4) $\AA, b=9.12204$ (11) $\AA, c=29.1165$ (3) $\AA, \beta=90.0056(9)^{\circ}, V=1014.899$ (19) $\AA^{3}, Z=4, R(F)=$ $0.048, w R\left(F^{2}\right)=0.131$, CCDC deposition number $=1915104$.
Crystal data for $4 \mathrm{C}_{13} \mathrm{H}_{8} \mathrm{~N}_{2} \mathrm{~S}, M_{\mathrm{r}}=224.27$, triclinic, $P \overline{1}$ (no. 2), $a=6.7661$ (3) $\AA, b=9.2454$ (6) $\AA, c=16.4453$ (12) $\AA$, $\alpha$ $=90.393(5)^{\circ}, \beta=92.650(5)^{\circ}, \gamma=99.674(5)^{\circ}, V=1012.92$ (11) $\AA^{3}, Z=4, R(F)=0.128, w R\left(F^{2}\right)=0.386$, CCDC deposition number $=1915105$.

\section{ASSOCIATED CONTENT}

\section{S Supporting Information}

The Supporting Information is available free of charge on the ACS Publications website at DOI: 10.1021/acsomega.9b02621.

Chromatogram for the compound mixture $3 / 4$ and thermal ellipsoid plots for compounds 1, 2, and 4; crystal structures; and proton and carbon spectra for compounds $1,2,3 / 4$, and 8 (PDF)

\section{AUTHOR INFORMATION}

\section{Corresponding Author}

*E-mail: m.j.plater@abdn.ac.uk.

ORCID $\odot$

M. John Plater: 0000-0003-0204-9695

William T. A. Harrison: 0000-0003-2253-4866

Notes

The authors declare no competing financial interest.

\section{ACKNOWLEDGMENTS}

We are grateful to BASF (Cheadle UK) for the donation of Irgacure PAG 103, the UK National Mass Spectrometry Service, and the UK National Crystallography Service.

\section{REFERENCES}

(1) Ito, H.; Willson, C. G.; Fréchet, J. M. J. New UV resists with negative or positive tone. Digest of Technical Papers of 1982 Symposium on VLSI Technology, 1982; pp 86-87.

(2) Ito, H. Chemical amplification resists:history and development within IBM. IBM J. Res. Dev. 2000, 44, 119-130.

(3) Ito, H.; Willson, C. G. Chemical amplification in the design of dry developing resist materials. Technical Papers of SPE Regional Technical Conference on Photopolymers, 1982; pp 331-353.

(4) Ito, H.; Willson, C. G. Chemical amplification in the design of dry developing resist materials. Polym. Eng. Sci. 1983, 23, 1012-1018.

(5) Ito, H.; Willson, C. G. Polymers in Electronics; Davidson, T., Ed.; ACS Symposium Series 242; American Chemical Society: Washington, D.C, 1984; pp 11-23.

(6) Ito, H. Chemical amplification resists for microlithography. Microlithography/Molecular Imprinting; Advances in Polymer Science; Springer, 2005; Vol. 172, pp 37-245.

(7) Robinson, A. P. G.; Lawson, R. A. Materials and Processes for Next Generation Lithography; Palmer, R. E., Ed.; Frontiers of Nanoscience; Elsevier; 2016; Vol. 11.

(8) Crivello, J. V.; Lam, J. H. W. Diaryliodonium salts. A new class of photoinitiators for cationic polymerisation. Macromolecules 1977, 10, $1307-1315$

(9) Crivello, J. V.; Lam, J. H. W. Photoinitiated cationic polymerization with triarylsulfonium salts. J. Polym. Sci., Polym. Chem. Ed. 1979, 17, 977-999.

(10) Crivello, J. V.; Reichmanis, E. Photopolymer materials and processes for advanced technologies. Chem. Mater. 2014, 26, 533548.

(11) Crivello, J. V. Cationic polymerisation: Iodonium and sulfonium salt photoinitiators. Initiators-Poly-Reactions-Optical Activity; Advances in Polymer Science; Springer, 1984; Vol. 62, pp $1-48$. 
(12) Crivello, J. V. Latest developments in the chemistry of onium salts. In Radiation Curing in Polymer Science and Technology; Fouassier, J. P., Rabek, J. F., Eds.; Elsevier: Barking, U.K., 1993; Vol. 2, pp 435472.

(13) Crivello, J. V.; Dietliker, K. Photoinitiators for Free Radical Cationic and Anionic Photopolymerization; Bradley, G., Ed.; Wiley: Weinheim, Germany, 1999; pp 125-141.

(14) Klikovits, N.; Knaack, P.; Bomze, D.; Krossing, I.; Liska, R. Novel photoacid generators for cationic photopolymerisation. Polym. Chem. 2017, 8, 4414-4421.

(15) Lalevée, J.; Mokbel, H.; Fouassier, J.-P. Recent developments of versatile photoinitiating systems for cationic ring opening polymerisation operating at any wavelengths and under low light intensity sources. Molecules 2015, 20, 7201-7221.

(16) Asakura, T.; Yamoto, H.; Ohwa, M.; Birbaum, J.-L.; Dietliker, K.; Tanabe, J. Oxime Derivatives and the Use Thereof as Latent Acids. U.S. Patent 6,512,020B1; Ciba Speciality Chemicals Corporation, March 28, 2001.

(17) Dietliker, K.; Rutsch, W.; Berner, G.; Hunziker, M.; Demmer, C. G. Oxime Sulfonates Containing Reactive Groups. U.S. Patent 4,736,055A; Ciba-Geigy Corporation, April 11, 1986.

(18) Schroer, H.; Goliasch, K.; Beck, U. Process for the preparation of 2-oxoiminophenylacetonitrile. U.S. Patent 4,233,233A; Bayer Aktiengesellschaft, Nov 11, 1980.

(19) Dietliker, K.; Kunz, M.; Yamato, H.; De Leo, C. Alkylsulfonyloximes for high-resolution I-line photoresists of high sensitivity. U.S. Patent 0,013,974A1; Ciba Speciality Chemicals Corporation, Jan 22, 2004.

(20) Sawamoto, D.; Kimijima, K.; Murata, K.; Kozaki, Y.; Oishi, T. Oxime ester compound and photopolymerisation initiator containing the same. U.S. Patent 0,283,520A1; Adeka Corporation, Oct 5, 2017.

(21) Lamanna, W. L.; Kessel, C. R.; Savu, P. M.; Cheburkov, Y.; Brinduse, S.; Kestner, T. A.; Lillquist, G. J.; Parent, M. J.; Moorhouse, K. S.; Zhang, Y.; Birznieks, G.; Kruger, T.; Pallazzotto, M. C. Proceedings of SPIE, 2002; Vol. 4690, p 817.

(22) Reichmanis, E.; Nalamasu, O.; Houlihan, F. M. Organic materials challenges for $193 \mathrm{~nm}$ imaging. Acc. Chem. Res. 1999, 32, 659-667.

(23) Sanders, D. P. Advances in patterning materials for $193 \mathrm{~nm}$ immersion lithography. Chem. Rev. 2010, 110, 321-360.

(24) Li, L.; Liu, X.; Pal, S.; Wang, S.; Ober, C. K.; Giannelis, E. P. Extreme ultraviolet resist materials for sub-7 $\mathrm{nm}$ patterning. Chem. Soc. Rev. 2017, 46, 4855-4866.

(25) Nandi, S.; Yogesh, M.; Reddy, P. G.; Sharma, S. K.; Pradeep, C. P.; Ghosh, S.; Gonsalves, K. E. A photoacid generator integrated terpolymer for electron beam lithography applications: sensitive resist with pattern transfer potential. Mater. Chem. Front. 2017, 1, 18951899.

(26) Lawson, R. A.; Noga, D. E.; Tolbert, L. M.; Henderson, C. L. Nonionic photoacid generator behaviour under high-energy exposure sources. J. Micro/Nanolithogr., MEMS, MOEMS 2009, 8, 043010.

(27) Kasahara, K.; Kosma, V.; Odent, J.; Xu, H.; Yu, M.; Giannelis, E. P.; Ober, C. K. Recent progress in nanoparticle photoresist development for EUV lithography. Proceedings of SPIE. Extreme Ultraviolet (EUV) Lithography IX, 2016; Vol. 9776, UNSP 977604.

(28) Cho, Y. J.; Ouyang, C. Y.; Krysak, M.; Sun, W. J.; Gamez, V.; Sierra-Alvarez, R.; Ober, C. K. Solvent development processing of chemically amplified resists: chemistry, physics, and polymer science considerations. Proceedings of SPIE. Advances in Resist Materials and Processing Technology XXVIII, 2011; Vol. 7972, p 797205.

(29) Jiang, J.; Thompson, M. O.; Ober, C. K. Line width roughness reduction by rational design of photoacid generator for submillisecond laser post-exposure bake. Proceedings of SPIE. Advances in Patterning Materials and Processes XXXI, 2014; Vol. 9051, p $90510 \mathrm{H}$.

(30) Krysak, M.; Jung, B.; Thompson, M. O.; Ober, C. K. Investigation of acid diffusion during laser spike annealing with systematically designed photoacid generators. Proceedings of SPIE.
Advances in Resist Materials and Processing Technology XXIX, 2012; Vol. 8325, p 83250M.

(31) Sun, W. J.; Gamez, V. M.; Otero-Gonzalez, L.; Cho, Y.; Ober, C. K.; Sierra-Alvarez, R. Biodegradability, cytotoxicity, and physiochemical treatability of two novel perfluorooctane sulfonate-free photoacid generators. Arch. Environ. Contam. Toxicol. 2013, 64, 187197.

(32) Sun, W. J.; Cho, Y.; Krysak, M.; Ouyang, C. Y.; Sierra-Alvarez, R.; Ober, C. K. Lithography performance and environmental compatibility of PFOS-free photoacid generators. Green Mater. 2017, 5, 173-181.

(33) Ishiji, Y.; Hikita, M. Positive photosensitive resin composition, method for forming cured film, cured film, organic EL display device and liquid crystal display device. U.S. Patent 0,045,616A1, 2011.

(34) Sakita, K.; Kikuchi, W.; Yumoto, M.; Hikita, M. Photosensitive resin composition, oxime sulfonate compound, method for forming cured film, organic EL display device, and liquid crystal display device. EP2613198A1, 2011.

(35) Yoshida, K.; Amemiya, T.; Yamada, S.; Nakagawa, M. Photosensitive resin composition, method for producing cured film, cured film, liquid crystal display device, organic electroluminescent display device, and touch panel. WO2017115606, 2016.

(36) Ito, H.; Fujimoto, S.; Kawabe, Y. Pattern forming method, etching method and method for producing capacitance-type input device. U.S. Patent 0,199,458A1, 2012.

(37) Ishikawa, T.; Noda, K.; Ohuchi, Y.; Chisaka, H.; Shiota, D.; Maeda, Y.; Imoto, T.; Fujita, K.; Akai, Y. Imidazole compound, metal surface treatment liquid, metal surface treatment method, and laminate production method. U.S. Patent 0,247,334A1, 2015.

(38) Asakura, T.; Yamato, H.; Tanaka, K.; Takahashi, R.; Kura, H.; Nakano, T. Studies on photodecomposition of an oxime sulfonate. $J$. Photopolym. Sci. Technol. 2014, 27, 227-230.

(39) Nakashima, T.; Tsuchie, K.; Kanazawa, R.; Li, R.; Iijima, S.; Galangau, O.; Nakagawa, H.; Mutoh, K.; Kobayashi, Y.; Abe, J.; Kawai, T. Self-contained photoacid generator triggered by photocyclization of triangle terarylene backbone. J Am Chem Soc 2015, 137, 7023-6.

(40) Harrison, W. T. A.; Plater, M. J.; Yin, L. J. Investigations of new potential photo-acid generators: crystal structures of 2-[(E)-2phenylethenyl]phenol (orthorhombic polymorph) and (2E)-3-(2bromophenyl)-2-phenylprop-2-enoic acid. Acta Crystallogr., Sect. E: Crystallogr. Commun. 2016, 72, 407-411.

(41) Li, R; Nakashima, T.; Kawai, T. A self-contained photoacid generator for super acid based on photochromic terarylene. Chem. Commun. 2017, 53, 4339-4341.

(42) Mallory, F. B.; Mallory, C. W. Photocyclisation of stilbenes and related molecules. Organic Reactions; Dauben, W. G., Ed.; Wiley, J. \& Sons, 1984; Vol. 30, pp 1-440.

(43) Liu, L.; Yang, B.; Katz, T. J.; Poindexter, M. K. Improved methodology for photocyclization reactions. J. Org. Chem. 1991, 56, 3769-3775.

(44) BASF plc, Europe GmbH, PO Box 4, Earl Road, Cheadle Hulme, Cheadle SK8 6QG, UK (via Thomas Pulver, BASF Kaisten AG, Kaisten, 5082, CH). 